\title{
Weather index insurance will offset heat-induced rice loss under global warming
}

Jing Zhang

$\mathrm{N} / \mathrm{A}$

Z ZHANG ( $\nabla$ zhangzhao@bnu.edu.cn)

Key Laboratory of Environmental Change and Natural Disaster MOE, Faculty of Geographical Science, Beijing Normal University

Chenzhi Wang

Peking University https://orcid.org/0000-0002-1756-4887

LiangLiang Zhang

Beijing Normal University

Fulu Tao

Chinese Academy of Sciences https://orcid.org/0000-0001-8574-0080

\section{Article}

Keywords: weather index insurance, global warming, rice

Posted Date: August 4th, 2021

DOl: https://doi.org/10.21203/rs.3.rs-737881/v1

License: (c) (i) This work is licensed under a Creative Commons Attribution 4.0 International License.

Read Full License 


\title{
Weather index insurance will offset heat-induced rice loss under global warming
}

\begin{abstract}
Global warming threatens food security through causing increasing and severe yield losses from heat extremes, especially for smallholder rice-cropping farmers in Asia. Weather index insurance (WII) could transfer weather-related risks, secure farms' income, and recover agricultural systems. Under future warming scenarios, however, the related studies are still scarce. Here, compared with the historical period (1961-2010), heat-induced loss will approximately increase by up to $5 \%, 18 \%$, and $26 \%$ at 2100 under three shared socioeconomic pathways of CMIP6, respectively. As an ex-ante strategy, county-specific WII will improve farmers' income by up to $13 \%$ and stabilize it by up to $36 \%$, even though the pure premium rate of WII will increase by $10 \%$ at 2050 and by $30 \%$ at 2100 . For the first time, our study proves WII is one effective adaptation strategy for the most susceptible farmers under global warming and has the potential to be applied for other crops and countries.
\end{abstract}

\section{Introduction}

Global warming demonstrates increasingly frequent and severe threats to agricultural systems. A number of studies have assessed the impacts of temperature trends and heat extremes on crop yield in a warming world ${ }^{1-7}$. Specifically, heat extremes consistently commits huge yield losses ${ }^{5,7}$, while the temperature trends show relatively moderate or even positive impacts in some areas ${ }^{1,4,8}$. Thus, how to adapt heat extremes in the future is of the most crucial concern to many governments in terms of ensuring national food security under global warming. As one of the most important stable crops in the world, rice is highly sensible to extreme heat. Previous experiments have shown that 
extreme high temperatures during the reproductive period, even for just a few hours, can lead to spikelet sterility in rice $^{9}$. Given that main rice-producing regions are located in the east and southeast Asia, a region dominated by the poor smallholder farmers, farmers are particularly susceptible to heat extremes because of their high dependence on agriculture, low productivity, poor infrastructure, and worsening global warming ${ }^{10,11}$. Therefore, effective adaptation strategies to mitigate adverse effects of heat extremes on rice production are urgently needed in the east and southeast Asia.

Technological adaptations, such as selecting hazard-tolerant crop varieties, changing sowing dates, and upgrading irrigation systems, have been confirmed that can reduce crop damages from climate change ${ }^{12-14}$. However, the economic adaptations have rarely been touched for the future warming, for example, crop insurance. Crop insurance has been widely accepted as one of the most importantly economic adaptations for agricultural systems ${ }^{15,16}$. Particularly, weather index insurance (WII) has dominated its greater appeals than traditional indemnity-based insurance in terms of compensating weather-specific loss for the last decades ${ }^{17,18}$. WII pays indemnities based on an objective weather index that is highly correlated with actual losses, which can avoid farmlevel loss assessments and proceed indemnities timely and economically ${ }^{17-19}$. More importantly, WII is one sustainable risk-transfer tool because its direct and immediately financial payments can in turn promote other technological adaptations to sustain agricultural systems ${ }^{15,20}$. But, our knowledge on its efficiency in the warming future is still very limited. Considering that the current WII markets are generally underdeveloped and could offer tremendous potential for smallholder farmers in developing countries, filling the gap of WII's effectiveness will facilitate the research of economic adaptations to global warming, and furtherly broaden national governments' navigations to ensure food security. 
Using three shared socioeconomic pathways (SSP) in Phase 6 of the Coupled Model Intercomparison Project (CMIP6), we focus on future heat extremes in the largest smallholder ricecropping country in Asia, China (Fig. SI-1). By applying crop model and machine learning, we try to answer the following questions: (1) what features of rice responses to heat stress (called as heat vulnerability $\left.{ }^{21}\right)$; (2) how much heat-induced yield loss $\left(Y_{\text {Hloss }}\right)$ and economic loss in the future; and (3) how about efficiency after implementing WII in future.

\section{Results}

The heat vulnerability of rice in China. Our analysis reveals that nonlinear relationship between the $Y_{\text {Hloss }}$ and heat extremes (calculated as the heating growing degree days, HGDD; see the Methods) is consistently positive in all rice-cropping zones (Fig. 1), but varies by locations. For single rice (Fig. 1a-e) and late rice (Fig. 1k-o), the slope of the trend line decreases from north to south, suggesting that the heat vulnerability became less sensitive in lower-latitude areas. Notably, the minimum slopes are found in Yunnan for single rice (Fig. 1e) and in Nanling and Huanan for late rice (Fig. 1n and 1o). For early rice (Fig. 1f-j), the infection point of the trend line moves from north to south, with the standardized HGDD around 0.8 in Yanjiang and Lianghu (Fig. 1f and 1g) and around 0.6 in Zhemin, Nanling, and Huanan (Fig. 1h-j). The heat vulnerabilities reveal spatially specific response process of rice to heat extremes, which highlights the importance of discrete loss estimation for each cropping zone based on its explicit vulnerability. 

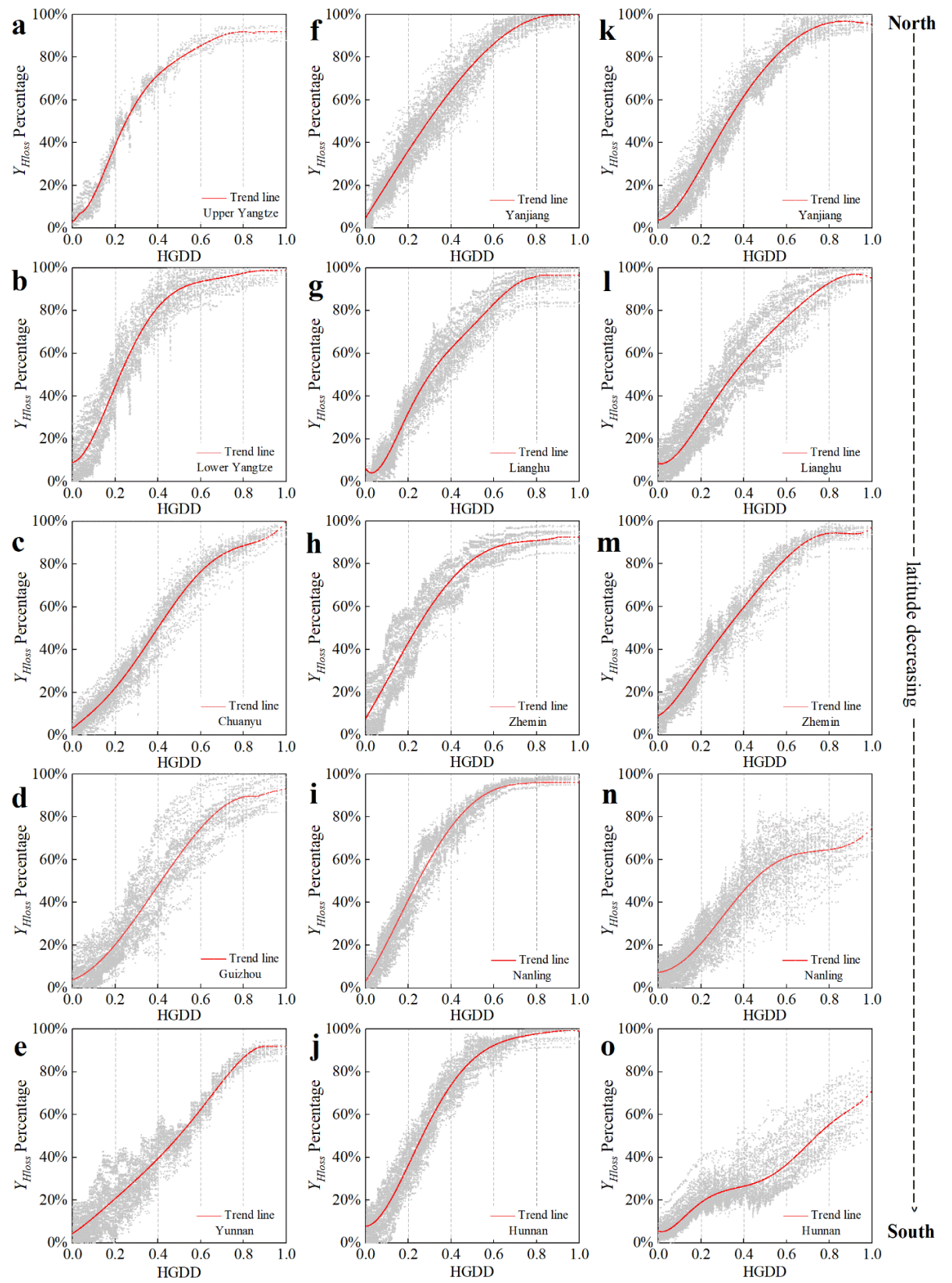

Fig. 1 The heat vulnerability of rice at different rice-cropping zones for (a-e) Single Rice, (f-j) Early Rice,

and (k-o) Late Rice. The heat extremes are calculated as HGDD at $x$ axis and is standardized by the min-max normalization. The $Y_{\text {Hloss }}$ percentage at y axis is $Y_{\text {Hloss }}$ divided by the no-stress yield (the potentially maximum yield, see details in the Methods). 
Future heat-induced yield and economic losses. Future $Y_{\text {Hloss }}$ is determined by heat vulnerability and its intensity (Fig. SI-2). We find that the $Y_{\text {Hloss }}$ varies significantly by rice zones under different warming scenarios (Fig. 2). Notably, $Y_{\text {Hloss }}$ decreases from north to south under all future scenarios for single and late rice (Fig. 2a-e and Fig. 2k-o), but not for early rice (Fig. 2f-j). For single rice, the $Y_{\text {Hloss }}$ could be up to $10.1 \% \pm 7.8 \%$ (average \pm standard deviation) in near future (2021-2050) and $30.1 \% \pm 15.6 \%$ in mid-far future (2051-2100) in Lower Yangtze (Fig. 2b), with the minimums respectively of $1.7 \% \pm 1.6 \%$ and $1.7 \% \pm 1.9 \%$ in Yunnan (Fig. 2e). Similarly, $Y_{\text {Hloss }}$ of late rice will reach up to $9.3 \% \pm 6 \%$ in near future and $27.5 \% \pm 14.7 \%$ in mid-far future in Yanjiang (Fig. $2 \mathrm{k}$ ), with the minimum of $2.9 \% \pm 2.5 \%$ in both near and mid-far future in Nanling (Fig. $2 \mathrm{n}$ ). As for early rice, $Y_{\text {Hloss }}$ will be as high as $9.8 \% \pm 8.5 \%$ in near future and $26.6 \% \pm 19.4 \%$ in mid-far future in the southernmost zone (Huanan, Fig. $2 \mathrm{j}$ ), while the minimum is $2.4 \% \pm 2.1 \%$ in both near and mid-far future in Zhemin (Fig. 2h). Moreover, the maximum $Y_{\text {Hloss }}$ is consistently under shared socioeconomic pathway 5-8.5 (SSP5-8.5), while the minimums under SSP1-2.6.

In comparison to the historical period (1961-2010), $Y_{\text {Hloss }}$ will change slightly in near future but increase dramatically in mid-far future. In near future, the maximum increase of $Y_{\text {Hloss }}$ is in Lower Yangtze for single rice (by 3.8\%, 5.3\%, and 5.6\% SSP5-8.5, SSP3-7.0, and SSP1-2.6, respectively; Fig. 2b), in Huanan for early rice (by 2.5\%, 3.9\%, and 4.8\%; Fig. 2j), and in Lianghu for late rice (by $3.8 \%, 4.8 \%$, and 5.3\%; Fig. 2I). In mid-far future, such maximum increase is in Lower Yangtze for single rice (5.3\%, 17.5\%, and 25.6\%; Fig. 2b), in Lianghu for early rice (by 1.9\%, 14.3\%, and 23.1\%; Fig. 2g), and in Yanjiang for late rice (by 4.9\%, 16.4\%, and 24.3\%; Fig. 2k). Overall, the difference between two future periods in terms of $Y_{\text {Hloss }}$ is up to $20 \%$. Overall, the projected losses highlight the importance of spatially- and temporally-specific adaptations to mitigate negative impacts of heat extremes. 

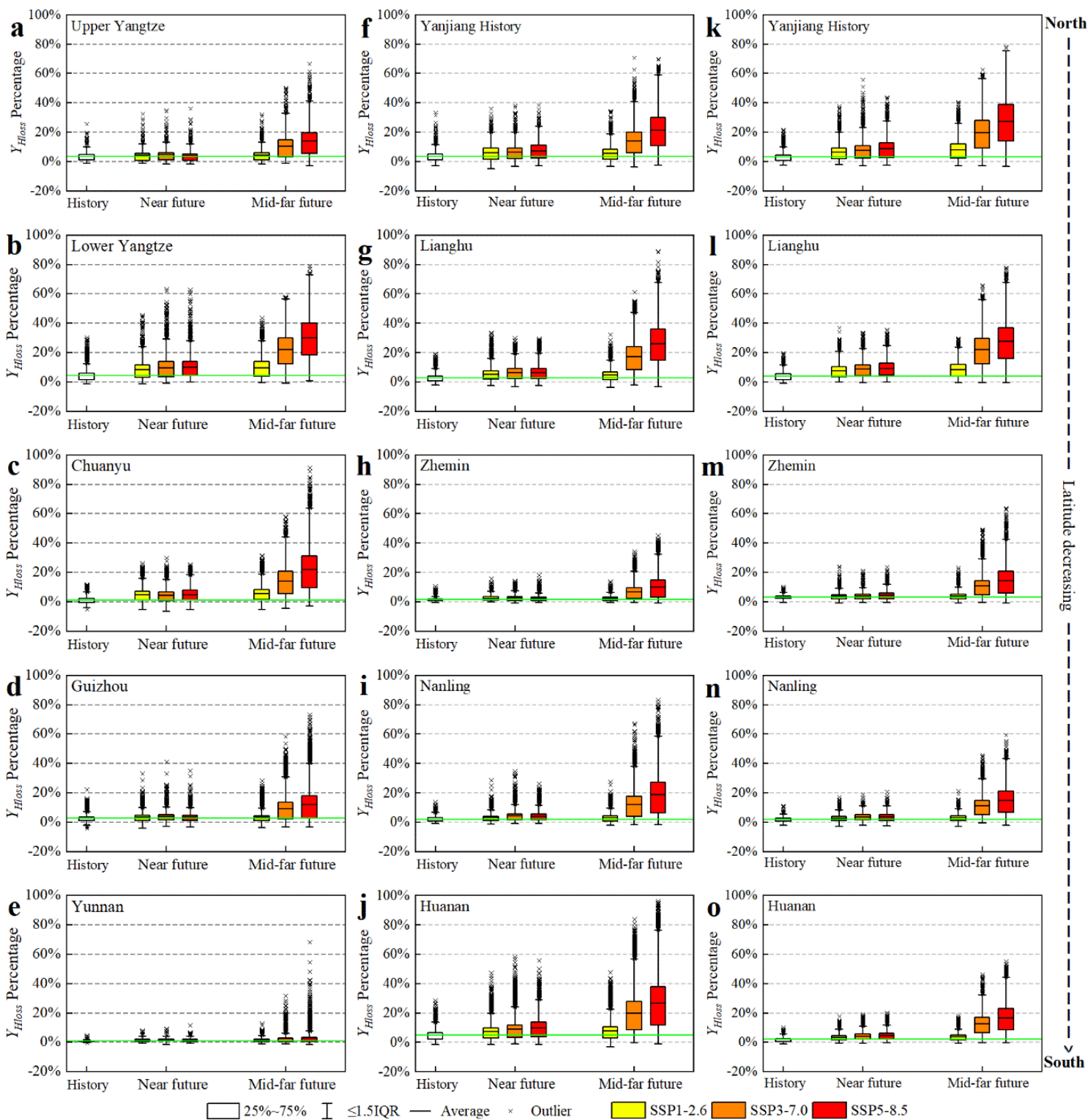

Fig. 2 The estimation of $Y_{\text {Hloss }}$ during history period (1961-2010), near future (2021-2050), and mid-far future (2051-2100) at different rice-cropping zones for (a-e) Single Rice, (f-j) Early Rice, and (k-o) Late

Rice. Green lines indicate the average of $Y_{\text {Hloss }}$ in the history period. Box plots include the average (horizontal line in box), interquartile range (IQR, edge of box), whiskers to the extent of 1.5IQR, and outliers. 


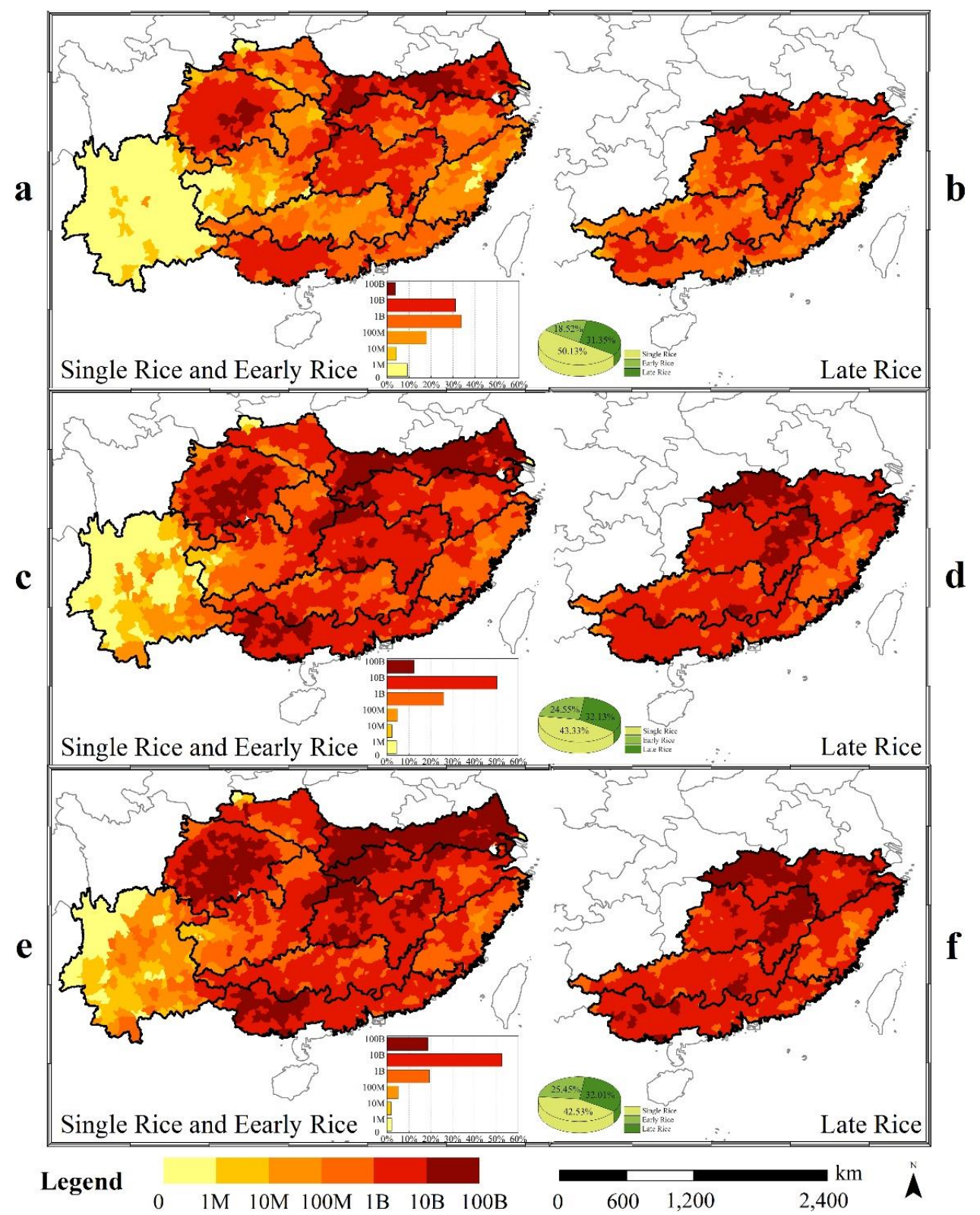

Fig. 3 Total heat-induced economic loss during 2021-2100 at the county scale for rice in China: (a-b) SSP1-

2.6, (c-d) SSP3-7.0, and (e-f) SSP5-8.5. M: million; B: billion. Bar graphs reflect the percentage of counties with different-level economic losses. Pie graphs shows the percentage of economic loss for single rice, early rice, and late rice. 
Assuming a constant rice price and cropping area from 2010 onward, we map the total economic losses from heat extremes during the period 2021-2100 at the county scale (Fig. 3). The economic losses range from thousands to billions RMB and show identically geographical characteristics under different SSP scenarios. The total economic loss of rice due to heat extremes is 1536 billion RMB, 569 billion RMB, and 966 billion RMB under SSP1-2.6 for single rice, early rice, and late rice, respectively (Fig. 3a and b); then increases to 3161 billion RMB, 1794 billion RMB, and 2357 billion RMB under SSP3-7.0 (Fig. 3c and d); finally reaches at 4358 billion RMB, 2613 billion RMB, and 3300 billion RMB under SSP5-8.5 (Fig. 3e and f). Hence, the single rice will experience the greatest economic loss, even though its percentage decreases from $50.1 \%$ via $43.3 \%$ to $42.5 \%$ (Fig. 3 ) as future SSP became warming. Moreover, the economic loss of early rice is lower than that of late rice under all warming scenarios, even though its percentage increases from $18.5 \%$ via $24.6 \%$ to $25.5 \%$ (Fig. 3) as future SSP became warming.

The economic losses show a similar spatial pattern under all warming scenarios, whereby counties suffering high economic loss (>1billion RMB) are mainly located in Chuanyu and Lower Yangtze for single rice, in Yanjiang, Lianghu, and Huanan for early rice and late rice (Fig. 3). Actually, the percentage of such counties increases from $34.8 \%$ via $62.6 \%$ to $71.3 \%$ as future SSP became warming. Conversely, Yunnan experiences the smallest economic loss under all warming scenarios, with economic losses < 1billion RMB in most counties. 


\section{The WII pure premium rate (PPR) and efficiency.}
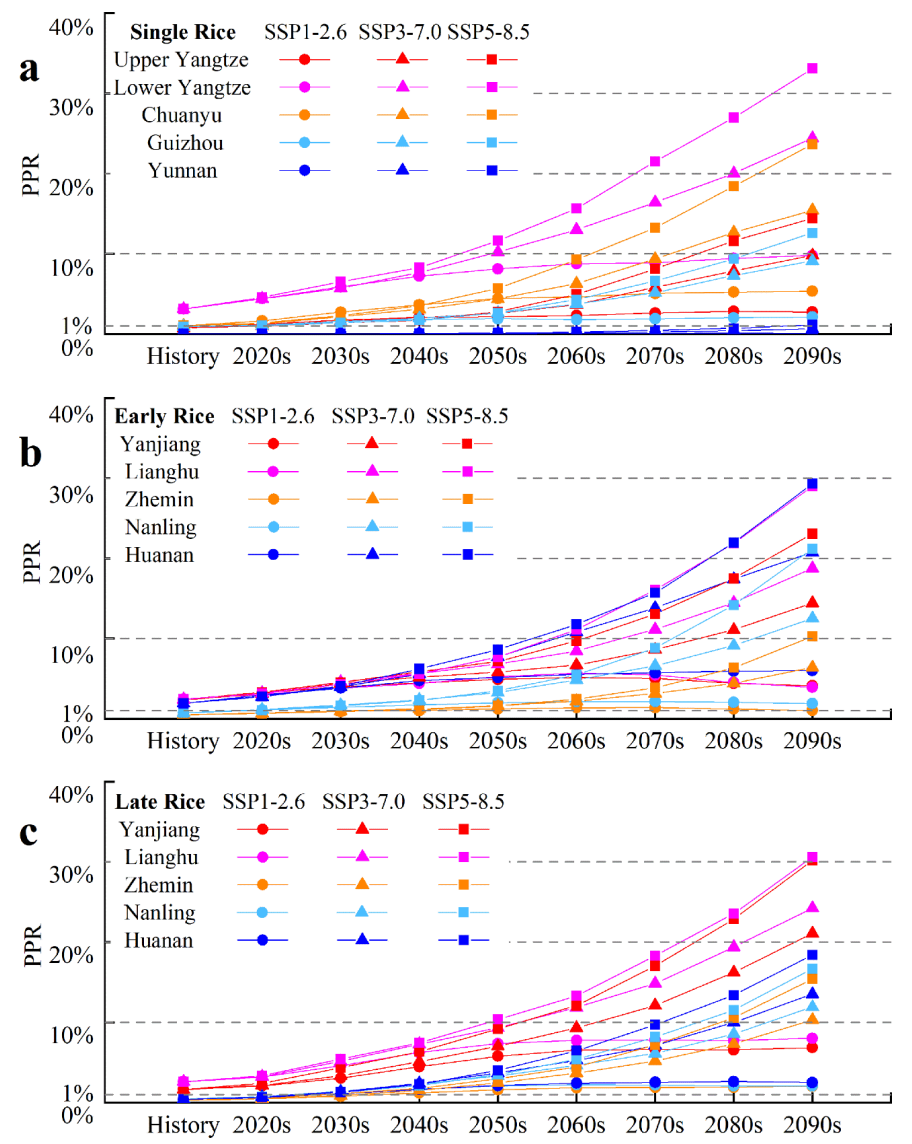

Fig. 4 The PPR at zonal scale for (a) Single Rice, (b) Early Rice, and (c) Late Rice. The zonal PPR is the average PPR of all counties within one rice-cropping zone 
Table 1 Future insurance efficiency measured by (a) CTE and (b) MRSL

(The rice-cropping zones were sequenced as latitude decreasing)

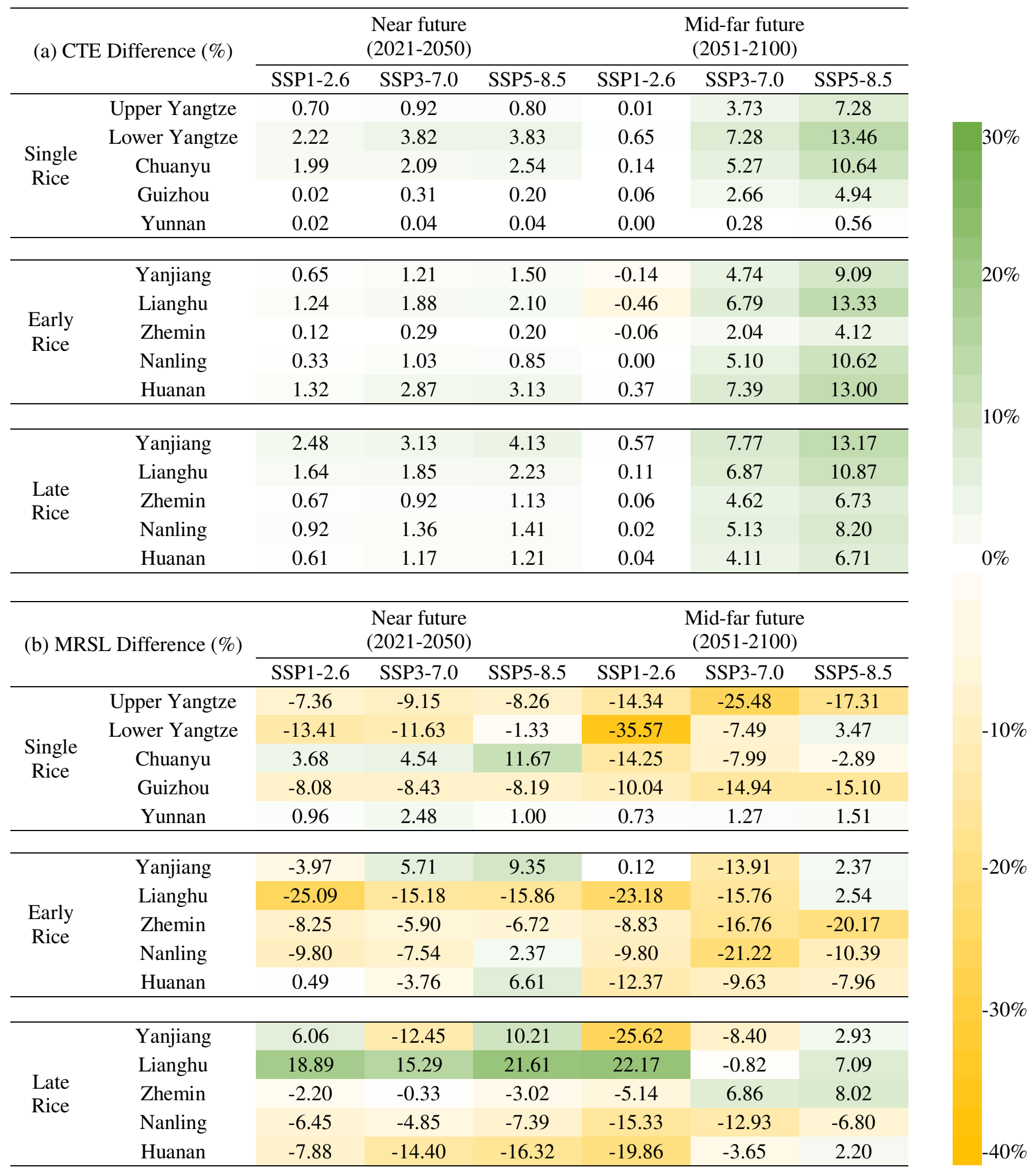


PPR is the key factor of one WII product and determines its efficiency, thus the PPR is estimated for each county and year, then integrated into the zonal and decadal scale (Fig. 4). The zonal PPR mostly increases with global warming over time. During history period, the PPR was less than 5\% in all rice-cropping zones. Especially, the PPR was below $1 \%$ in $60 \%$ of zones, including four single rice zones (Upper Yangtze, Chuanyu, Guizhou, and Yunnan; Fig. 4a), two for early rice zones (Zhemin and Nanling; Fig. 4b), and three late rice zones (Zhemin, Nanling, and Huana; Fig. 4c). Around 2050s, PPR becomes higher than $10 \%$ in a few rice-cropping zones, for example, single rice in Lower Yangtze under SSP5-8.5. Finally, most PPRs under SSP3-7.0 and SSP5-8.5 will exceed $10 \%$ by 2100 , while all PPRs under SSP1-2.6 remain below $10 \%$. Besides, the highest PPRs is in Lower Yangtze for single rice (33\%, Fig. 4a), in Lianghu and Huanan for early rice (29\%, Fig. 4b), and in Yanjiang and Lianghu for late rice (30\%, Fig. 4c). More interestingly, several PPRs under SSP1-2.6 slightly decrease or remain constant in mid-far future (2050-2100), reflecting the changes of heat disasters over this period (Fig. SI-2).

We calculate conditional tail expectation (CTE) difference and the mean root square loss (MRSL) difference to analyze the average and variability changes of farmers' income before and after applying WII at county scale (details see Methods), and then integrate them into the zonal scale (Table 1). We find that most CTE differences are positive, while MRSL differences are negative, suggesting that applying WII for each county and year will effectively improve farmers' income and reduce their variabilities under future global warming. Specifically, CTE differences become greater in the mid-far future than it in the near future under SSP3-7.0 and SSP5-8.5, indicating that WII can reduce more risks as global warming becomes more severe (Table 1a). Spatially, the CTE differences are relatively greater in higher-latitude areas for single rice and late rice, while they are mostly greater in lower-latitude areas for early rice (Table 1a). Although most 
MRSL differences are negative, they tend to become positive in more rice-cropping zones under the warmest SSP scenarios. For example, in near future, positive MRSL differences are identified in three early rice zones under SSP5-8.5, but only one zone under the other SSPs (Table 1b); while in mid-far future, positive MRSL is identified in four late rice zones under SSP5-8.5, but only one zone for the rest SSPs (Table 1b). These results highlight that applying WII will fail to ensure the stability of farmers' income under the warmest scenario, even though it significantly offsets such negative impacts under the SSP1-2.6 and 3-7.0 scenarios.

\section{Discussion}

Our study verifies that WII can offset farmers' loss from global warming. Future warming scenarios may cause hundreds to thousands billion losses in RMB (Fig. 3), which varies among rice-cropping zones due to zonal-specific vulnerabilities (Fig. 2) and heat disasters (Fig. SI-2). Facing with such projected economic loss, WII demonstrates its efficiency through improving farmers' income by up to $13 \%$ and stabilizing it by up to $36 \%$ (Table 1 ).

To achieve WII's efficiency, we estimate the annually dynamic PPR change under global warming and downscale WII from the province to county. Previous studies have assessed the impact of global warming on PPR, but mainly focused on PPR change per unit temperature

increment. For example, Tack et al. ${ }^{22}$ has pointed the averagely marginal effect of temperature warming on premium rate was $39 \%$ per Celsius for corn in U.S. Considering the nonlinear relationship between global warming and premium rate, tracking the annually dynamic changes in PPR is significantly necessary for accurately estimating future impacts. Our study for the first time explores the dynamic PPR by 2100 , so that future PPR can be designated at any time under various warming scenarios. For example, we find the increase in PPR will be up to 20\% under SSP5-8.5 
during mid-far period (Fig. 4c), while it is only 1.68\% under SSP1-2.6 at the same period (Fig. 4a). As for the downscaled WII, our results facilitate the research of WII implementation at the county scale over large areas. The current policy of crop insurance premium is "One province, one rate" in China, which means the same premium rate is applied to the entire province for a given $\operatorname{crop}^{23}$. However, this policy ignores the spatial heterogeneity of farmers' risk within the province. On the other side, field-level data are the most suitable for WII, but consistent series of such data over a long period are not available worldwide ${ }^{24,25}$. Thus, crop insurance at the county scale has been receiving more attention, as evidenced by the expanding range of insurance products at county scale in the United States ${ }^{22,26}$. An increasing number of pilot WII programs have also been introduced at the county scale in China ${ }^{23,27}$, but the covered area was limited to several counties or within one province. This study is the first to estimate WII PPR and its efficiency at the county scale across large regions (up to 15 provinces, 242 million ha) in China. Overall, the annual PPR at the county scale can provide the temporally- and spatially-specific guide for national governments in implementing WII to ensure national food security under global warming.

However, the corresponding high PPR suggests that multiple supports will be needed for applying WII in the future. Specifically, the 2050s would be a turning point for WII, because at that point the WII becomes less economical with the zonal PPR exceeding $10 \%$ and even higher than $30 \%$ by 2100 . Given that the normal PPR of crop insurance generally ranges from $1 \%$ to $10 \%^{22,23,28}$, the increasing PPR would inevitably result in a higher need for government subsidy on crop insurance in the future. Crop insurance market would be thin without government subsidies on premium, and the current level of government subsidy has already hindered its growth in most developing countries, including China. Therefore, future WII needs multiple supports to achieve its effectiveness, which may include but are not limited to: involving private commercial insurance 
and reinsurance companies to compete on price ${ }^{29}$, incorporating banks or microfinance institutions to provide credit for smallholder farmers ${ }^{19}$, and cultivating heat-tolerant rice varieties to decrease future $\mathrm{PPR}^{18}$.

Even though WII can offset rice yield losses from heat extremes under all SSPs, farmers should caution the worst warming scenario. The future economic growth ${ }^{30}$ and heat-induced loss (Fig. 2 and 3) both vary hugely among three SSPs. Focusing on Chinese economy under CMIP6, Chen et al. ${ }^{31}$ has estimated that future GDP at purchasing power parity (GDP-PPP) per capita in China is highest under SSP5-8.5, followed by SSP1-2.6, and the minimum for SSP3-7.0 (around 40\% of GDP-PPP per capita under SSP5-8.5). Interestingly, our study reveals that economic loss from rice heat is the highest under SSP5-8.5, followed by SSP3-7.0 (around 70\% of economic loss under SSP5-8.5), and the minimum under SSP1-2.6 (Fig. 5). Thus, farmers under SSP3-7.0 might face a heavier burden in terms of adapting to heat stress than under SSP5-8.5. Regarding that more significant rice losses are in the mid-far future (2051-2100, Fig. 2), governments should be aware of this challenge and help farmers to prepare for the worst future scenarios, that is, a mid-far future under SSP3-7.0.

The main uncertainty of this study comes from the combined effect of temperature and $\mathrm{CO}_{2}$. The elevated $\mathrm{CO}_{2}$ and increased temperature have the opposite impacts on crop growth. Numerous studies have indicated that the elevated $\mathrm{CO}_{2}$ can increase crop yield through improving the leaf photosynthesis rate and the number of panicles per unit area ${ }^{32-34}$, while high temperature decreases rice yield through causing infertile spikelet ${ }^{9}$. Taking the highest elevated $\mathrm{CO}_{2}$ under three SSPs as example, we find that the elevated $\mathrm{CO}_{2}$ does improve rice yield (Fig. SI-3), but the $Y_{\text {Hloss }}$ percentage changes slightly (Fig. SI-4) because the elevated $\mathrm{CO}_{2}$ also increases the no-stress rice yield (the potentially maximum yield, see details in the Methods). In this context, our estimations 
on future WII PPR (Fig. 4) and its efficiency (Table 1) are still creditable, because both of them are based on $Y_{\text {Hloss }}$ percentage (Fig. 2). Nevertheless, analysis for the long-term future, rather than only one decade with the highest elevated $\mathrm{CO}_{2}$ (Fig. SI-4), should be furtherly conducted to explore more possible impacts from the elevated $\mathrm{CO}_{2}$.

Overall, future crop loss will increase as temperature warming under three SSPs, and the SSP3-7.0 might be the worst scenario for farmers to adapt. Unfortunately, the COVID-19 pandemic, the increasing regional conflicts, and constrained international trades in recent years are likely to drag our world toward SSP3-7.0. Faced with such projected threats, this study provides a downscaling and replicable method to evaluate the effectiveness of WII for crops under climatic risks, and proves WII to be one positive adaptation strategy for the most susceptible smallholder farmers. Our results can greatly inspire farmers and governments to take actively measures to ensure global food security in a warming world. 


\section{Methods}

Study area. Based on the administrative borders, cropping systems, and geological conditions, we divided the study area into 10 rice-cropping zones (five for single rice: Upper Yangtze, Lower Yangtze, Chuanyu, Guizhou, and Yunnan; five for double rice: Yanjiang, Lianghu, Zhemin, Nanling, and Huanan; Fig. SI-1) in the southern China. Cropping systems and geological conditions were nearly consistent within each zone. There are 1100 counties and 15 provinces in total, covering more than $80 \%$ Chinese paddy field based on land use datasets $(35,36)$. Constrained by data availability, crop model in this study could run at only 154 counties for single rice and 228 counties for double rice (shown as red dots in Fig. SI-1), which were defined as "red-dotted" counties.

Data. To simulate $Y_{\text {Hloss }}$, we developed one hybrid simulation process combining crop model (the Crop-Weather relationship over a Large Area for rice ${ }^{37}$, MCWLA-Rice) and machine learning $\left(\mathrm{XGBoost}^{38}\right)$. Multisource data were required in this hybrid simulation process. Firstly, we calibrated and validated MCWLA-Rice for each "red-dotted" county during the period of 19902010 because of the limited data availability. Data for these "red-dotted" counties included daily weather data from Chinese Meteorological Administration (the maximum temperature, the minimum temperature, solar radiation, precipitation, wind speed, and vapor pressure), the location information (longitude and latitude), and soil texture and hydrological properties data ${ }^{37,39}$. In addition, the MCWLA-Rice calibration required the remote sensing data (GLASS leaf area index ${ }^{40}$, LAI), the retrieved phenology dates based on GLASS LAI ${ }^{41}$, and rice yields from local yearbooks. All above data were collected or resampled to county scale. Next, to simulate $Y_{\text {Hloss }}$ based on the calibrated MCWLA-Rice and the trained XGBoost, the no-stress and heat-stress weather scenarios 
were generated from daily weather data during the same period (1990-2010). Details are in the following section "Scenario-driven yield loss estimation based on MCWLA-Rice". Similarly, data details of the XGBoost training process are in the section "Training and testing XGBoost". As for the historical (1961-2010) and future (2021-2100) projected weather scenarios, we downloaded CMIP6 database ${ }^{42}$, which provides a range of future global warming scenarios based on various assumptions regarding economic growth, climate mitigation efforts, and global governance. To consider a range of possible futures, we used five best bias-adjusted models with $0.5^{\circ}$ resolution ${ }^{43,44}$ : GFDL-ESM4, IPSL-CM6A-LR, MPI-ESM1-2-HR, MRI-ESM2-0, and UKESM10-LL. Each dataset has three Shared Socioeconomic Pathways ${ }^{45}$ (SSP) with different radiative forcing pathways by $2100^{46}$ : SSP $1-2.6$ ( less than $2^{\circ} \mathrm{C}$ warming; low end forcing pathway), SSP3 - 7.0 (around $4{ }^{\circ} \mathrm{C}$ warming; medium to high end forcing pathway), and SSP5 - 8.5 (around $5^{\circ} \mathrm{C}$ warming; high end forcing pathway). All CMIP6 data were also resampled to the county scale. The average from five-model simulation results were used in this study. Moreover, the future period was divided into the near future (2021-2050) and the mid-far future (2051-2100).

Scenario-driven yield loss estimation based on MCWLA-Rice. The calibration and validation of crop model is the preliminary stage for yield loss estimation. In this study, we calibrated and validated MCWLA-Rice for each "red-dotted" county (shown as red dots in Fig. SI-1). Moreover, the 2/3 from 1990-2010 was randomly selected for calibration, while the rest for validation. The sub-model component method ${ }^{47}$ sequentially calibrated the phenology module, the LAI module, and the yield module for MCWLA-Rice. The calibration and validation results were well satisfying (SI Section4). 
We determined that the averages of weather variables during 1990-2010 made up the nostress weather scenario. Next, the extreme heat event was randomly generated for 1000 times based on its definition: the daily maximum temperature $\left(T_{\max }\right)$ was higher than $35^{\circ} \mathrm{C}$ for at least three days during the heading-flowing stage ${ }^{48}$, where the upper threshold of $T_{\max }$ was set as $45^{\circ} \mathrm{C}$ so that sufficient extreme heat events could be generated. After adding the extreme heat event into the nostress weather scenario, each county would have one no-stress scenario and 1000 heat-stress scenarios. Driven by no-stress and heat-stress weather scenarios, the calibrated MCWLA-Rice estimated the no-stress and heat-stress yields; with the difference between them being regarded as the $Y_{\text {Hloss }}$. Furthermore, the weather index (HGDD) for the extreme heat event was calculated as following ${ }^{48,49}$ :

$$
\mathrm{HGDD}=\sum_{i=1}^{\mathrm{n}}\left(T_{i}^{\max }-35\right)
$$

where $T_{i}^{\max }$ was the daily maximum temperature during the heading-flowering stage at day $i ; n$ was higher than 2, indicating duration of the extreme heat event.

Training and test XGBoost. Constrained by the data availability, MCWLA-Rice could only be calibrated for a small fraction of counties to generate $Y_{\text {Hloss }}$. Therefore, we must develop a more general and flexible method to estimate $Y_{\text {Hloss }}$ for all counties in order to conduct a more comprehensive investigation. Thus, we collected the county-scale $Y_{\text {Hloss }}$ and HGDD, as well as weather variables and location information (latitude and longitude), to train and test XGBoost model for each rice-cropping zone. Here, the weather variables were same as those used for MCWLA-Rice, including the daily maximum temperature, minimum temperature, precipitation, radiation, wind speed, and vapor pressure. In addition, weather variables were individually calculated into six weather indices through summing weather variable from the transplanting date 
to the beginning of extreme heat event, representing weather conditions before the extreme heat event.

The county-scale $Y_{\text {Hloss }}$, HGDD, six weather indices, and location information were randomly divided into $70 \%$ for training and $30 \%$ for testing. The former was used to optimize the hyperparameters of the XGBoost through GridSearchCV with 10-fold cross-validation; the latter was used to evaluate the models' prediction ability. The trained regional XGBoost was sufficiently accurate to estimate the county-scale $Y_{\text {Hloss }}$ within each zone (Fig. SI-8). Moreover, we replaced $Y_{\text {Hloss }}$ with the county-scale yield and trained the regional XGBoost again, so that the county-scale yield also could be well predicted (Fig. SI-9).

Constructing heat vulnerability. Vulnerability can characterize the process and mechanisms whereby a crop responds to a specific natural hazard. Previous studies mostly developed crop vulnerability curves through using the historical records from very limited studied areas or pooling many field trials into only one vulnerability curve. Their results were event-specific or less accurate, because limited records they obtained probably did not include various event intensities and crop vulnerability might vary over large and spatially heterogeneous areas. To obtain more accurate and regional-specific vulnerability, we generated the full range of scenario-driven $Y_{\text {Hloss }}$ for each county based on the hybrid simulation process and 1000 heat-stress scenarios; and estimated the heat vulnerability through using the least square method to fit the relationship between HGDD and $Y_{\text {Hloss }}$ for each rice-cropping zone. Therefore, our vulnerability results could mechanically reflect all yield losses from heat stress across large and homogeneous areas. Moreover, we were able to apply the method into various crops and hazards, obtain spatially 
specific vulnerability for a better understanding of crop's response to natural hazards, and consequently provide a quick loss estimates for scientific decisions-making of governments.

Prediction of yield loss and economic loss. Using the hybrid simulation process of MCWLARice and XGBoost, the historical and future $\mathrm{Y}_{\text {Hloss }}$ could be estimated as far as the local location information, the transplanting date, the heading-flowering stage, and daily weather variables were available. However, the county-scale transplanting date and heading-flowering stage were only available during 1990-2010 for "red-dotted" counties (shown as red dots in Fig. SI-1). Therefore, we assumed that the rice-cropping systems and field managements were static from 2010. For "red-dotted" counties, the average transplanting dates during 1990-2010 were calculated as the transplanting dates for the historical (1961-1989) and future period (2021-2100); The MCWLARice simulated yearly heading-flowering stages for each "red-dotted" county for the historical (1961-1989) and future period (2021-2100). Thus, the transplanting dates and heading-flowering stages for the other counties could be determined by the closest "red-dotted" county. Finally, as for daily weather variables, both historical and future daily weather variables were from CMIP6 models (details in Data Section) to avoid systematic errors.

Assuming that rice price and area were constant from 2010, the economic loss caused by heat extremes $\left(E_{\text {Hloss }}\right)$ was calculated as followings:

$$
E_{\text {Hloss }}=Y_{\text {Hloss }} \times P \times \text { Area }
$$

Where, $Y_{\text {Hloss }}$ was the average heat-induced yield loss from five CMIP6 models in the current year. $P$ was the nationally minimum purchase price in $2010: 2.54 \mathrm{RMB} / \mathrm{kg}$ for single rice, 2.02 $\mathrm{RMB} / \mathrm{kg}$ for early rice, and $2.21 \mathrm{RMB} / \mathrm{kg}$ for late rice. Area was the rice-cropping area for each county based on paddy field data from land use datasets of China (Fig. SI-1). 
Prediction of insurance pure premium rate (PPR) and efficiency. Based on county-scale $Y_{\text {Hloss }}$, the PPR was calculated as follows ${ }^{50}$ :

$$
\mathrm{PPR}=\frac{\mathrm{E}\left(Y_{\text {Hloss }}\right)}{\lambda^{*} Y_{\text {no-stress }}}
$$

Where in this study, $\mathrm{E}\left(Y_{\text {Hloss }}\right)$ is the expected value of $Y_{\text {Hloss }}$ and the non-parametric kernel density approach was used to estimate it based on $Y_{\text {Hloss }}$ in the last 30 years.; $\lambda$ was coverage level and set as 100\%; and $\mathrm{Y}_{n o-s t r e s s}$ was the no-stress yield (the potentially maximum yield).

We also calculated the farmers' income at the county scale. The income without and with WII was calculated using by formula (4) and (5), respectively:

$$
\begin{aligned}
& I_{\text {before }}=P \times Y \\
& I_{\text {after }}=P \times Y+\beta-\theta
\end{aligned}
$$

Where for each year, $I_{\text {before }}$ and $I_{\text {after }}$ was farmers' income before and after applying WII. $P$ was the nationally minimum purchase price. $Y$ was county-scale rice yield. $\beta$ was the insurance indemnity for extreme heat disasters, that is, $P \times Y_{\text {Hloss }} . \theta$ was yearly insurance premium and equaled to (insurance liability $\times$ premium rate). Here, the insurance liability was the max value of rice yield, that is, $P \times Y_{\text {no-stress }}$; the premium rate was PPR without considering administrative cost loading. Therefore, formula (5) also could also be expressed as follows:

$$
I_{\text {after }}=P \times\left(Y+Y_{\text {Hloss }}-\mathrm{PPR} \times Y_{\text {no-stress }}\right)
$$

To compare differences between $I_{\text {before }}$ and $I_{\text {after }}$, we analyzed $I_{\text {before }}$ and $I_{\text {after }}$ through using the CTE and MRSL as previous studies ${ }^{51-53}$. Notably, CTE measured the average of farmers' income and MRSL for semi-variance.

$$
\begin{gathered}
\mathrm{CTE}=\frac{1}{\mathrm{~T}} \times \sum_{\mathrm{t}=1}^{\mathrm{T}} I \\
\mathrm{MRSL}=\sqrt{\frac{1}{\mathrm{~T}} \times \sum_{t=1}^{\mathrm{T}}[\max (P \times \bar{Y}-I, 0)]^{2}}
\end{gathered}
$$


Where, $\mathrm{T}$ was 30 for near future (2021-2050) and 50 for mid-far future (2051-2100); $\bar{Y}$ was the average yield in near future or mid-far future; $P$ was the nationally minimum purchase price; $I$ was $I_{\text {before }}$ or $I_{\text {after }}$, so that we could have $\mathrm{CTE}_{\text {before }}, \mathrm{CTE}_{\text {after }}, \mathrm{MRSL}_{\text {before }}$, and $\mathrm{MRSL}_{\text {after }}$. After applying WII, the positive CTE difference $\left(\mathrm{CTE}_{\text {after }}\right.$ minus $\left.\mathrm{CTE}_{\text {before }}\right)$ and negative MRSL difference $\left(\mathrm{MRSL}_{\text {after }}\right.$ minus $\mathrm{MRSL}_{\text {before }}$ ) both indicated that WII was effective.

The fertilization effect from $\mathbf{C O}_{2}$. The $\mathrm{CO}_{2}$ concentration remained 382ppm during our simulation process; however, it mostly increases under three SSPs in the future. To conduct whether the elevated $\mathrm{CO}_{2}$ affected our results in this study, we incorporated the highest $\mathrm{CO}_{2}$ concentration to estimate $\mathrm{CO}_{2}$-fertilized $Y_{\text {no-stress }}, Y_{\text {Hloss }}$, and future yearly rice yield. Here, the highest $\mathrm{CO}_{2}$ concentration is $458 \mathrm{ppm}$ in 2050s, 750ppm in 2090s, and 1027ppm in 2090s under SSP1-2.6, SSP3-7.0, and SSP5-8.5, respectively ${ }^{54}$.

\section{Competing interests}

The authors declare no competing interests. 


\section{References}

1. Lobell, D. B. et al. Climate trends and global crop production since 1980. Science 333, 616$620(2011)$.

2. Gourdji, S. M., Sibley, A. M., \& Lobell, D. B. Global crop exposure to critical high temperatures in the reproductive period: historical trends and future projections. Environmental Research Letters 8, 024041 (2013).

3. Deryng, D. et al. Warren R. Global crop yield response to extreme heat stress under multiple climate change futures. Environmental Research Letters 9, 034011 (2014).

4. Moore, F. C. \& Lobell, D. B. The fingerprint of climate trends on European crop yields. Proc. Natl. Acad. Sci. 112, 2670-2675 (2015).

5. Lesk, C. Rowhani, P. \& Ramankutty, N. Influence of extreme weather disasters on global crop production. Nature 529, 84-87 (2016).

6. Zhao, C. et al. Temperature increase reduces global yields of major crops in four independent estimates. Proc. Natl. Acad. Sci. 114, 9326-9331 (2017).

7. Vogel, E. et al. The effects of climate extremes on global agricultural yields. Environmental Research Letters 14, 054010 (2019).

8. Agnolucci, P. \& De Lipsis, V. Long-run trend in agricultural yield and climatic factors in Europe. Climatic Change 159, 385-405 (2020).

9. Jagadish, S. K., Craufurd, P. Q., \& Wheeler, T. R. High temperature stress and spikelet fertility in rice (Oryza sativa L.). Journal of experimental botany 58, 1627-35 (2007).

10. Barnett, B. J., \& Mahul, O. Weather index insurance for agriculture and rural areas in lowerincome countries. American Journal of Agricultural Economics 89, 1241-1247 (2007). 
11. Aryal, J. P. et al. Climate change and agriculture in South Asia: Adaptation options in smallholder production systems. Environment, Development and Sustainability, 1-31 (2019).

12. Kurukulasuriya, P. et al. Will African agriculture survive climate change?. The World Bank Economic Review 20, 367-388 (2006).

13. Iglesias, A. et al. From climate change impacts to the development of adaptation strategies: challenges for agriculture in Europe. Climatic Change 112, 143-168 (2012).

14. Challinor, A. J. et al. Improving the use of crop models for risk assessment and climate change adaptation. Agricultural systems 159, 296-306 (2018).

15. Panda, A. et al. Adaptive capacity contributing to improved agricultural productivity at the household level: Empirical findings highlighting the importance of crop insurance. Global Environmental Change 23, 782-790 (2013).

16. Falco, S. D. et al. Crop insurance as a strategy for adapting to climate change. Journal of Agricultural Economics 65, 485-504 (2014).

17. Barnett, B. J. \& Mahul, O. Weather index insurance for agriculture and rural areas in lowerincome countries. American Journal of Agricultural Economics 89, 1241-1247 (2007).

18. Carter, M. et al. Index insurance for developing country agriculture: a reassessment. Annual Review of Resource Economics 9, 421-438 (2017).

19. Marr, A. et al. Adoption and impact of index-insurance and credit for smallholder farmers in developing countries: A systematic review, Agricultural Finance Review 76, 94-118 (2016).

20. Jensen, N. \& Barrett, C. Agricultural index insurance for development. Applied Economic Perspectives and Policy 39, 199-219 (2017).

21. Porter, J. R. et al. Climate Change 2014: Impacts, Adaptation and Vulnerability: Contribution of Working Group II to the Fifth Assessment Report of the Intergovernmental Panel on Climate 
Change, (eds Field CB, et al.) (Cambridge Univ. Press, Cambridge, UK, 2014).

22. Tack, J., Coble, K. \& Barnett, B. Warming temperatures will likely induce higher premium rates and government outlays for the US crop insurance program. Agricultural economics $\mathbf{4 9}$, 635-647 (2018).

23. Zhou, X. H., Liao, P. \& Wang, K. Is the "One Province One Rate” premium policy reasonable for Chinese crop insurance? The case in Jilin Province. Journal of Integrative Agriculture 17, 1900-1911 (2018).

24. Holly Wang, H. \& Zhang, H. On the possibility of a private crop insurance market: A spatial statistics approach. Journal of Risk and Insurance 70, 111-124 (2003).

25. Tadesse, M. A., Shiferaw, B. A. \& Erenstein, O. Weather index insurance for managing drought risk in smallholder agriculture: lessons and policy implications for sub-Saharan Africa. Agricultural and Food Economics 3, 1-21 (2015).

26. Smith, A. B. \& Katz, R. W. US billion-dollar weather and climate disasters: Data sources, trends, accuracy and biases. Natural hazards 67, 387-410 (2013).

27. Guo, J. et al. Design of Temperature Insurance Index and Risk Zonation for Single-Season Rice in Response to High-Temperature and Low-Temperature Damage: A Case Study of Jiangsu Province, China. International journal of environmental research and public health 16, 1187 (2019).

28. Ozaki, V. A., Goodwin, B. K. \& Shirota, R. Parametric and nonparametric statistical modelling of crop yield: implications for pricing crop insurance contracts. Applied Economics 40, 11511164 (2008).

29. Mahul, O., Verma, N. \& Clarke, D. Improving farmers' access to agricultural insurance in India. World Bank Policy Research Working Paper, 5987 (2012). 
30. Okhrin, O., M. Odening, \& W. Xu. Systemic weather risk and crop insurance: The case of China. Journal of Risk and Insurance 80, 351-372 (2013).

31. Chen, Y., Liu, A., \& Cheng, X. Quantifying economic impacts of climate change under nine future emission scenarios within CMIP6. Science of the total environment 703, 134950 (2020).

32. Krishnan, P. et al. Impact of elevated $\mathrm{CO} 2$ and temperature on rice yield and methods of adaptation as evaluated by crop simulation studies. Agriculture, ecosystems \& environment 122, 233-242 (2007).

33. Toreti, A. et al. Narrowing uncertainties in the effects of elevated co 2 on crops. Nature Food 1, 775-782 (2020).

34. Ainsworth, E. A. \& Long, S. P. 30 years of free-air carbon dioxide enrichment (FACE): What have we learned about future crop productivity and its potential for adaptation?. Global Change Biology 27, 27-49 (2021).

35. Liu, J. Y. et al. Spatial and temporal patterns of China's cropland during 1990-2000: an analysis based on Landsat TM data. Remote sensing of Environment 98, 442-456 (2005).

36. Liu, J. Y. et al. Spatial patterns and driving forces of land use change in China during the early 21st century. Journal of Geographical Sciences 20, 483-494 (2010).

37. Tao, F. \& Zhang, Z. Climate change, high-temperature stress, rice productivity, and water use in Eastern China: a new superensemble-based probabilistic projection. J. Appl. meteorol. Clim. 52, 531-551 (2013).

38. Chen, T. Q. \& Guestrin, C. Xgboost: A scalable tree boosting system. In Proceedings of the 22nd ACM SIGKDD International Conference on Knowledge Discovery and Data Mining, ACM. 785-794 (2016).

39. Sanchez, P. A. et al. Digital soil map of the world. Science 325, 680-681 (2009). 
40. Liang, S. et al. A long-term Global LAnd Surface Satellite (GLASS) data-set for environmental studies. International Journal of Digital Earth 6, 5-33 (2013).

41. Luo, Y. C. et al. ChinaCropPhen $1 \mathrm{~km}$ : a high-resolution crop phenological dataset for three staple crops in China during 2000-2015 based on leaf area index (LAI) products. Earth System Science Data 12, 197-214 (2020).

42. Eyring, V. et al. Overview of the Coupled Model Intercomparison Project Phase 6 (CMIP6) experimental design and organization. Geoscientific Model Development 9, 1937-1958 (2016).

43. Lange, S. ISIMIP3BASD v2.4.1, https://doi.org/10.5281/zenodo.3898426, (2020).

44. Lange, S. Trend-preserving bias adjustment and statistical downscaling with ISIMIP3BASD (v1.0), Geoscientific Model Development 12, 3055-3070 (2019).

45. O’Neill, B. C. et al. The roads ahead: Narratives for shared socioeconomic pathways describing world futures in the 21st century. Global Environmental Change 42, 169-180 (2017).

46. Gidden, M. et al. Global emissions pathways under different socioeconomic scenarios for use in CMIP6: a dataset of harmonized emissions trajectories through the end of the century. Geoscientific Model Development 12, 1443-1475 (2019).

47. Zhang, J., Chen, Y. \& Zhang, Z. A remote sensing-based scheme to improve regional crop model calibration at sub-model component level. Agricultural Systems 181, 102814 (2020).

48. GB/T 21985-2008. Temperature index of high temperature harm for main crops. China Standards Press, Beijing. (In Chinese, 2008).

49. Wang, P. et al. How much yield loss has been caused by extreme temperature stress to the irrigated rice production in China?. Climatic Change 134, 635-650 (2016). 
50. Alan, P. K. \& Barry, K. G. Nonparametric estimation of crop insurance rates revisited. Am J Agric Econ 82, 463-478 (2000).

51. Vedenov, D. V. \& Barnett, B. J. Efficiency of weather derivatives as primary crop insurance instruments. Journal of Agricultural and Resource Economics 1, 387-403 (2004).

52. Adeyinka, A. A. et al. The viability of weather-index insurance in managing drought risk in rural Australia. International Journal of Rural Management 12, 125-42 (2016).

53. Benami, E. et al. Uniting remote sensing, crop modelling and economics for agricultural risk management. Nature Reviews Earth \& Environment 2, 140-159 (2021).

54. Xiao, D. P. et al. Designing high-yielding maize ideotypes to adapt changing climate in the North China Plain. Agricultural Systems 1,102805 (2020). 


\section{Supplementary Files}

This is a list of supplementary files associated with this preprint. Click to download.

- SupplementaryInfo.pdf 